\title{
On Solving the Problem of Mental Health Care with the Social Work Input
}

Liliya Klos, Larysa Klymanska, Nina Hayduk, Halyna Herasym

\author{
Lviv Polytechnic National University, Lviv, Ukraine
}

\begin{abstract}
Background: According to statistics, the number of the mentally disabled among the population is 4-5\% (World Health Organization, 2018). Complex social circumstances faced by a person with mental illness are incompatible with the values of a humane and tolerant attitude toward people with "otherness", which corresponds to the social problem definition (Rubington \& Weinberg, 1995, p. 4.). There is a need for social change.
\end{abstract}

Purpose: The study aims to identify possibilities and ways of bringing in social work in solving the problem of mental health care in Ukraine.

Methods: Theoretical research methods were used to determine the current state of constructing the mental health care problem to find out opinions of experts (psychiatrists, psychologists, persons with mental illness, and those from their surroundings) on the challenges and needs of the mentally disabled in Ukraine. Qualitative content analysis of the materials of narrative interviews with clients of the social organization and expert interviews was done to identify opportunities for involving social workers in solving the problem of mental health care by the example of Lviv.

Results: Researchers are unanimous in the conclusion that "life with mental illness is also a life with those serious social losses that accompany this illness" (Polskaya, 2004, p. 157). As of January 1, 2017, 1673328 residents of Ukraine were registered due to mental and behavioral disorders (Cabinet of Ministers of Ukraine, 2017). The hope for resolving acute problems in mental health care in Ukraine is associated with social work, focusing on the bio-psycho-socio-spiritual human nature.

Modern concepts of mental disability can be divided into two types: medical and social. The medical model attributes to individuals the status of "sick" and "deviant", who should be "corrected" or isolated from society. The social type of explanation recognizes mental disability due to the historical development and unjust society arrangement (Romanov \& Yarskaya-Smirnova, 2006). Hence, the change in the social status of people suffering from mental disability is possible only under the condition of change in the dominant perceptions of the "disease of the soul". Summarizing numerous works devoted to the study of the concepts of mental illness, we note that the content of these concepts has a significant degree of negative valence. By the definition of R. Farr (Farr \& Markova, (Ed.), 1995), the form of a social conception with a negative valence is a stigma.

In the process of problematization of social circumstances associated with people with mental illness, professionals-experts (psychiatrists and psychologists) play an ambiguous role creating medical stigma (Sas, 2007, pp. 373-375). Hospitalization largely contributes to reducing the variety of social roles of an individual to a single role - that of a patient, and forming a distorted, negative self-concept (Goffman, 1961).

It is important to return the "voice of a patient" to studies to understand the actual needs of the mentally disabled (Porter, 2008, p. 57). In 2017, a study of the thoughts of people with mental illness about the challenges experienced by them in their environment was conducted. The method of an in-depth, narrative interview was chosen, and clients of the daytime programme of the Center for rehabilitation and social adaptation ( 8 persons, three of whom are men, five - women; their age: $25-42$ years) were interviewed. A comparative analysis of the texts, their structural description, and the statements coding were done as a major procedure of the representation analysis. Our informants attributed the understanding and support of family, relatives, friends and neighbors to the main factors in confronting the illness. At the same time, the immediate environment demonstrates a stigmatized, biased attitude to people with mental illness, with their self-stigma being also present there.

An expert survey of social service providers dealing with health care issues of the mentally disabled in Lviv was also conducted. The sample comprised 10 experts, with a snowball sampling technique used. All the experts, representatives of 6 non-governmental organizations and 4 state institutions, stressed the need for counteracting stigmatization in the individual's environment, particularly by means of social rehabilitation.

Consequently, there is a need for involving social work as an instrument to overcome stigmatization / selfstigmatization in social inclusion of people with mental disability. Thus, there is also a need for training social workers for professional activity in mental health care.

To address the above need, the Department of Sociology and Social Work is introducing an MSW programme (specialization) in mental health care, with its main principles based on the Concept of the development of mental health care in Ukraine for the period up to 2030. This policy document emphasizes, in particular, the social workers' role strengthening and the development of professional competences in mental health care (Cabinet of Ministers of Ukraine, 2017). We rely on the advanced experiences in mental health care worldwide, with clinical social workers playing an important role in various institutions applying the client-centered approach (NASW, 2011). A social worker in mental health care is competent in different professional activity aspects, in particular, s/he applies the ethical principles of social work, engages, assesses, intervenes and evaluates interventions with individuals, families, groups, organizations, and 
communities (CalSWEC, 2011). The new educational programme is based on the value-oriented, clientcentered, competence-based approach, and evidence-based social work practice. The Clinic of Community Health is also being established based on Lviv Polytechnic. Conclusion: The findings show the need for the social work input in solving the problem of mental health care in Ukraine. Accordingly, the social work education is addressing the need.

Keywords: mentally disabled, social problem, social change, social work, destigmatization, social work education, social inclusion

\section{References}

Cabinet of Ministers of Ukraine (2017). Order No.1018 as of 27.12.2017 on the approval of The Concept of the development of mental health care in Ukraine for the period up to 2030. URL: https: //www.kmu.gov.ua/ua/npas/pro-shvalennya-koncepciyi-rozvit

Pol'skaya, N.A. (2004). The mentally ill in modern society: The problem of stigma. Sociological Journal, 1-2, 157.

Porter, R. (2008). The patient's view. The history of medicine "from below". V.Y. Shliumboma et al. (Eds.), Illness and health: New approaches to the history of medicine (pp. 41-72). SPb.: European University at St. Petersburg: Aleteya.

Romanov, P., \& Yarskaya-Smirnova, E. (2006). Disability policy: The social citizenship of the disabled in modern Russia. Saratov: Scietific Book.

Sas, T. (2007). Madness factory. Ekaterinburg: Ultra: Culture.

CalSWEC. (2011). Integrated Foundation \& Advanced Competencies for Public Mental Health in California. URL: http://calswec.berkeley. edu/files/uploads/ docx/ Mental\% 2520Health/02_mh_comps_formatted_final.pdf.

Goffman, E. (1961). Asylums. Essays on the social situation of mental patients and other inmates. N.Y.: Anchor Books.

Farr, R., \& Markova, I. (Ed.). (1995). Representations of health, illness and handicap in the mass media of communication: A theoretical overview. Chur, Switzerland: Harwoord Academic Publishers.

NASW. (2011). Center for Workforce Studies \& Social Work Practice. Social Workers in Mental Health Clinics \& Outpatient Facilities - occupational profile. Washington, DC: National Association of Social Workers. URL: https: //www.socialworkers.org

Rubington, E., Weinberg M. (1995). The study of social problems. Seven perspectives. NewYork; Oxford: Oxford University Press.

World Health Organization (2018). Mental health atlas 2017. Geneva. URL: https://creativecommons.org/licenses/by-nc-sa/3.0/igo 